\title{
Bioinspired Synthesis of Quasi-Two-Dimensional Monocrystalline Oxides
}

Yizhan Wang, Yeqi Shi, Ziyi Zhang, Corey Carlos, Chenyu Zhang, Karishma Bhawnani, Jun Li, Jingyu Wang, Paul M. Voyles, Izabela Szlufarska, Xudong Wang*

Department of Materials Science and Engineering, University of Wisconsin-Madison, Madison, Wisconsin 53706, United States. *Correspondence to: xudong.wang@wisc.edu

\section{Methods}

Reagents: All chemicals were purchased through Sigma-Aldrich and used without further purification.

Synthesis of $\mathrm{Bi}_{2} \mathrm{O}_{3}$ nanosheets: In a typical synthesis of $\mathrm{Bi}_{2} \mathrm{O}_{3}$ nanosheets, $15 \mathrm{~mL}$ aqueous solution containing $0.5 \mathrm{mM}$ bismuth nitrate and $25 \mathrm{mM}$ HMTA was prepared in a $24 \mathrm{~mL}$ glass vial. After complete dissolution, $8 \mu \mathrm{L}$ of mixed surfactants solution of SOS and OAM (9:1) was spread onto the surface of the growth solution. After $10 \mathrm{~min}$, the solution was placed in $60{ }^{\circ} \mathrm{C}$ oven, and the reaction was conducted for $100 \mathrm{~min}$.

Synthesis of $\mathrm{MnO}_{2}$ nanosheets: To synthesize $\mathrm{MnO}_{2}$ nanosheets, $15 \mathrm{~mL}$ aqueous solution containing $2 \mathrm{mM}$ potassium permanganate, $1 \mathrm{mM}$ sulfuric acid was prepared in a $24 \mathrm{~mL}$ glass vial. To this, $8 \mu \mathrm{L}$ of mixed surfactants of oleic acid and oleylamine (with a ratio of 9:1) was gently dropped on top of the water and left to evaporate for $10 \mathrm{~min}$. The vial was then capped tightly and placed in a $90{ }^{\circ} \mathrm{C}$ convection oven for 1 hours. The interface of the reaction solution was then sampled with arbitrary substrate for further characterization.

Synthesis of Ni doped ZnO nanosheets: In a typical synthesis, $15 \mathrm{~mL}$ aqueous solution containing $15 \mathrm{mM}$ nickel nitrate, $10 \mathrm{mM}$ zinc nitrate and $25 \mathrm{mM}$ HMTA was prepared in a $24 \mathrm{~mL}$ glass vial. Mixed surfactants solution of SOS and OAM with specific ratio (total concentration is $1.8 \mathrm{mM}$ ) was prepared in chloroform. Then $8 \mathrm{uL}$ of the mixed surfactants was dispersed on the solution surface. After the monolayer formed, the vial was capped to form a closed reaction environment and placed in a $60{ }^{\circ} \mathrm{C}$ convection oven for $100 \mathrm{~min}$ to harvest monocrystalline nanosheets, which could be then scooped using an arbitrary substrate for further characterization. Synthesis of $\mathrm{Fe}_{3} \mathrm{O}_{4}$ nanosheets: To $24 \mathrm{~mL}$ glass vial was added $15 \mathrm{~mL} \mathrm{FeCl}_{2}(1 \mathrm{mM})$ aqueous solution. Mixed surfactants solution of stearyl alcohol and oleylamine with a ratio 19:1 (total concentration is $1.8 \mathrm{mM}, 8 \mathrm{uL}$ ) prepared in chloroform was spread onto the precursor solution surface. After the monolayer was formed, the glass vial was placed in a sealed container. Then 5.6 wt \% ammonia solution was added into the container as a source of $\mathrm{NH}_{3}$ gas for the reaction at room temperature. $\mathrm{NH}_{3}$ gas diffused into the precursor solution surface increasing its $\mathrm{pH}$ for the crystal growth. After $3 \mathrm{~h}$ reaction, the film at the interface was then scooped using an arbitrary substrate for further characterization.

Table S1. Intramolecular parameters for amino group. $\mathrm{N}$ stands for the nitrogen atom in the center of amino group. $\mathrm{H}$ is the hydrogen atoms around the nitrogen atom in amino group. These parameters are directly from GROMOS 54A7 force field library.

$\begin{array}{ccc}\text { Molecule covalent bonds } & \mathbf{K}_{\mathbf{b}}\left(\mathbf{k J} \mathbf{~ m o l}^{-\mathbf{1}} \mathbf{n m}^{-\mathbf{2}}\right) & \mathbf{r}_{\mathbf{0}}(\mathbf{n m}) \\ \mathrm{CH}_{2}-\mathrm{N} & 376560 & 0.147 \\ \mathrm{~N}-\mathrm{H} & 374468 & 0.100\end{array}$




\begin{tabular}{|c|c|c|c|c|}
\hline Molecule angles & $\mathrm{K}_{\boldsymbol{\theta}}(\mathrm{kJ} \mathbf{J o}$ & \multicolumn{3}{|c|}{ 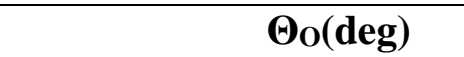 } \\
\hline $\mathrm{CH}_{2}-\mathrm{N}-\mathrm{H}$ & 376 & \multicolumn{3}{|c|}{109.500} \\
\hline $\mathrm{H}-\mathrm{N}-\mathrm{H}$ & 334 & \multicolumn{3}{|c|}{109.500} \\
\hline Molecule dihedral angles & $\mathbf{K}_{\varphi}\left(\mathbf{k J ~ m o l}^{-1}\right)$ & $\varphi_{0}(\operatorname{deg})$ & & $\mathbf{n}$ \\
\hline $\mathrm{H}-\mathrm{N}-\mathrm{CH}_{2}-\mathrm{CH}_{2}$ & 3.770 & 0.0 & & 6 \\
\hline $\mathrm{CH}_{2}-\mathrm{CH}_{2}-\mathrm{CH}_{2}-\mathrm{N}$ & 5.920 & 0.0 & & 3 \\
\hline
\end{tabular}

Table S2. Intermolecular Force Field Parameters. N stands for the nitrogen atom in the center of amino group. $\mathrm{H}$ is the hydrogen atoms around the nitrogen atom in amino group. The LennardJones parameters for $\mathrm{N}$ and $\mathrm{H}$ are directly from GROMOS 54A7 force field library. The charges for $\mathrm{N}$ and $\mathrm{H}$ are from Ref.6. The Lennard-Jones parameters for $\mathrm{Co}^{2+}$ ion are from Ref. 5. Interactions between water molecules are modeled using SPC/E force field.

\begin{tabular}{cccc}
\hline atoms(or groups $)$ & $\mathbf{\varepsilon}\left(\mathbf{k J ~ m o l}^{\mathbf{1}}\right)$ & $\boldsymbol{\sigma}(\AA)$ & $\mathbf{q}(\mathbf{e V})$ \\
\hline $\mathrm{N}$ & 0.6398 & 3.136 & -0.6220 \\
$\mathrm{H}$ & 0.0000 & 0.000 & +0.4180 \\
$\mathrm{Co}^{2+}$ & 0.0219 & 2.325 & -2.0000 \\
\hline
\end{tabular}

Simulation System: The simulation system contains 8,575 water molecules. Equilibrated water (without ions or surfactants) at $300 \mathrm{~K}$ in a periodic system with dimensions $8 \mathrm{~nm} \times 8 \mathrm{~nm} \times 4 \mathrm{~nm}$ was provided by GROMACS database; density of water is $1.002 \mathrm{~kg} / \mathrm{L}$. Equilibrated water is then placed into a larger box with dimensions $8 \mathrm{~nm} \times 8 \mathrm{~nm} \times 30 \mathrm{~nm}$, and $26 \mathrm{~nm}$ of vacuum is created above the water surface. Periodic boundary conditions are applied in all spatial directions and as a result the system has two vacuum-water interfaces. We place surfactant monolayer with different mixed ratios of SOS/OAM molecules at one of these interfaces in such a way that the chain of surfactant is in the vacuum layer and the head group is close to the water surface (initially the distance is less than $3.7 \AA$ ).

To prepare mixed surfactant monolayer with different SOS/OAM ratios, we first run two simulations to test the equilibrium time for different initial configurations. The results are shown in Figure S17. In Figure S17A and B we show two different starting structures for these simulations. Figure S17C and D show the corresponding configurations after $5 \mathrm{~ns}$ simulations in constant volume-constant temperature (NVT) ensemble at $300 \mathrm{~K}$. Regardless of the starting arrangement of surfactants, the final configurations are qualitatively similar after $5 \mathrm{~ns}$. In all the simulations reported in the main text, the mixed surfactant monolayer was prepared by putting SOS molecules on one side of the monolayer while OAM on the other side (similar to the configuration in Figure S17A). To ensure we reached an equilibrium configuration, we run NVT ensemble at $300 \mathrm{~K}$ for $32 \mathrm{~ns}$.

The surface area per molecule of this monolayer is controlled and set to be $29 \AA^{2}$. The number of $\mathrm{Co}^{2+}$ ions dissolved in water is consistent with the desired $\mathrm{Co}^{2+}$ density. $\mathrm{Na}^{+}$and $\mathrm{Cl}^{-}$ions are also added to the system. Specifically, the number of $\mathrm{Na}^{+}$ions is the same as the number of SOS surfactant molecules and the number of $\mathrm{Cl}^{-}$is chosen to balance the charge of OAM surfactant molecules and $\mathrm{Co}^{2+}$ ions. Ions are added to the system by replacing (i.e., deleting) random water molecules. Static energy minimization with the steepest descent algorithm was used first to relax the simulation box that contains water, surfactants, and ions. Subsequently, each system was 
equilibrated for $2 \mathrm{~ns}$ at $300 \mathrm{~K}$ in an NVT ensemble. After equilibration, we perform production runs and the reported measurements correspond to averages taken over the last $30 \mathrm{~ns}$ of simulations in NVT ensemble and with a 2 fs timestep. A modified Berendsen thermostat was applied to control the temperature. Particle-Mesh Ewald was utilized to treat the long-range electrostatic interactions and the cut-off in the Lennard-Jones interaction was $1 \mathrm{~nm}$ off.

The charge density near the monolayer and the roughness of the monolayer are calculated and averaged over the last $28 \mathrm{~ns}$ of each simulation. The charge density along the $\mathrm{z}$ direction (perpendicular to the water surface) is averaged over regions that are $0.15 \mathrm{~nm}$ in height and that have the same $\mathrm{x}$ and $\mathrm{y}$ dimensions as the entire monolayer. The roughness is calculated as the root mean square error of the $\mathrm{z}$ coordinate of the surfactant head-groups ( $\mathrm{S}$ atoms in SOS and N atoms in OAM).
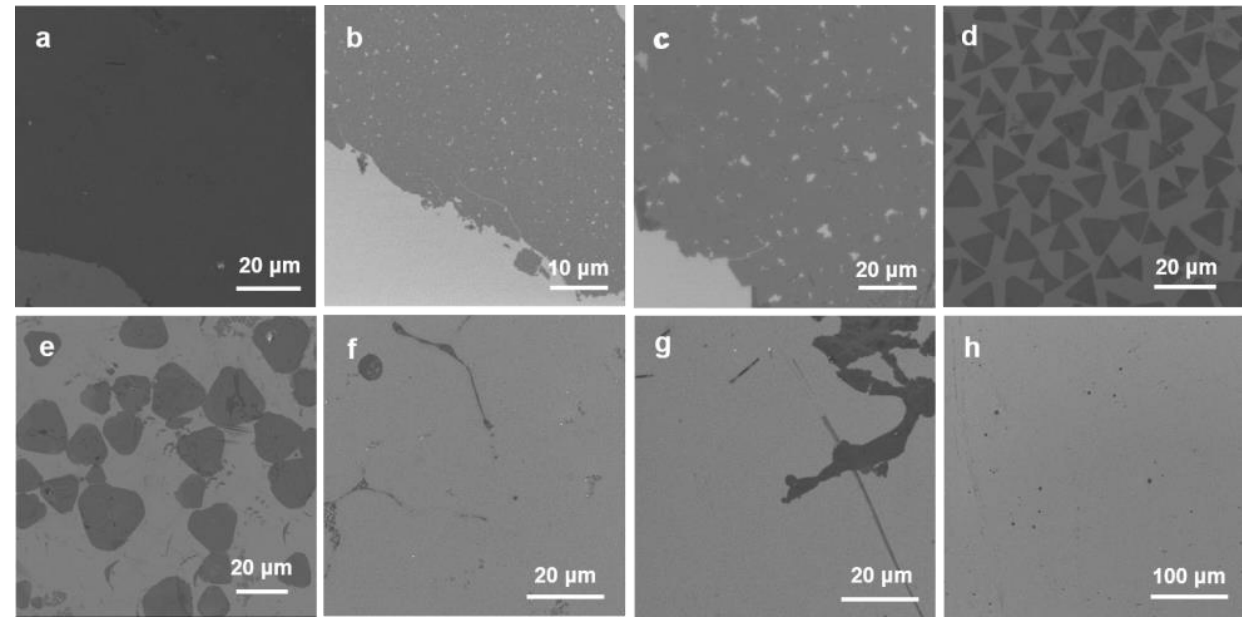

Figure S1. Cobalt hydroxide nanosheets growth with different ratio of mixed surfactants: a) SOS; b) SOS/OAM = 39:1; c) SOS/OAM = 19:1; d) SOS/OAM = 9:1; e) SOS/OAM = 7:3; f) $\mathrm{SOS} / \mathrm{OAM}=5: 5 ; \mathrm{g}$ ) SOS/OAM $=3: 7 ; \mathrm{h}$ ) OAM. All the synthesis was performed with $5 \mathrm{mM}$ $\mathrm{Co}\left(\mathrm{NO}_{3}\right)_{2}$ and $25 \mathrm{mM}$ HMTA at $60{ }^{\circ} \mathrm{C}$. 


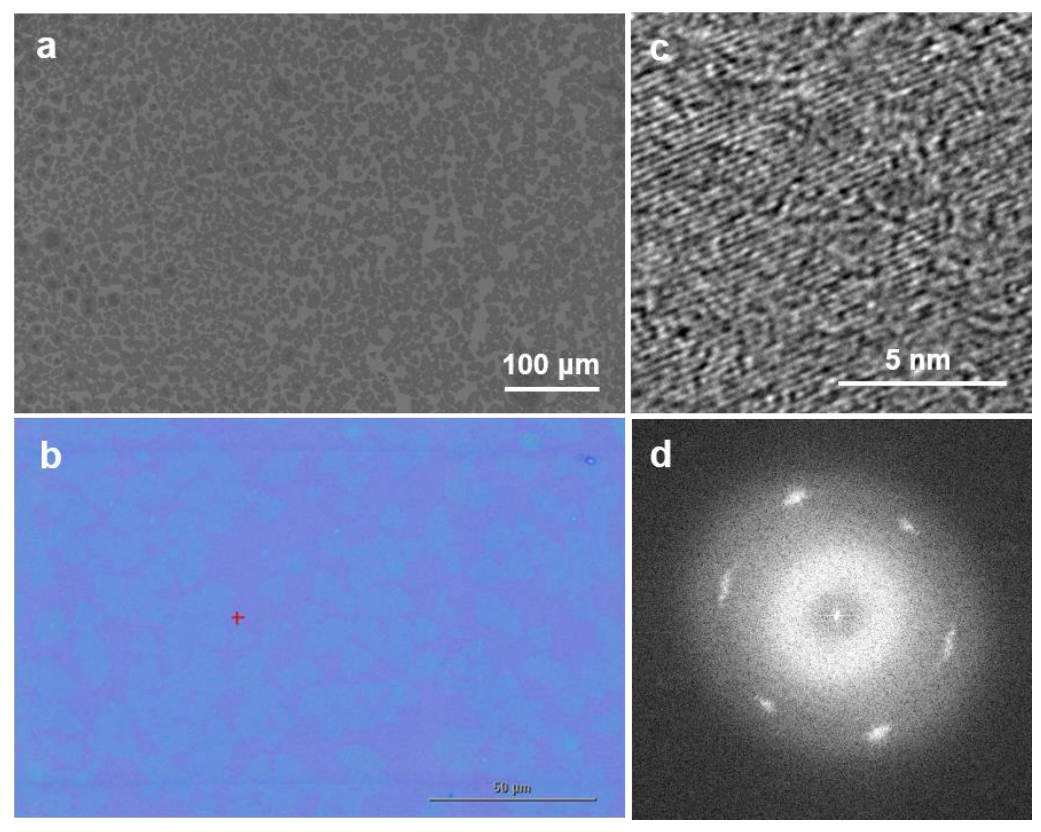

Figure S2. Co(OH)2 nanosheets synthesized by mixed monolayer of SOS/OAM = 9:1. a. Large scale image of $\mathrm{Co}(\mathrm{OH})_{2}$ triangle nanosheets; b. Optical microscope image of the triangle nanosheets; $\mathbf{c}$. TEM and $\mathbf{d}$. the corresponding FFT of the $\mathrm{Co}(\mathrm{OH})_{2}$ triangle nanosheets.
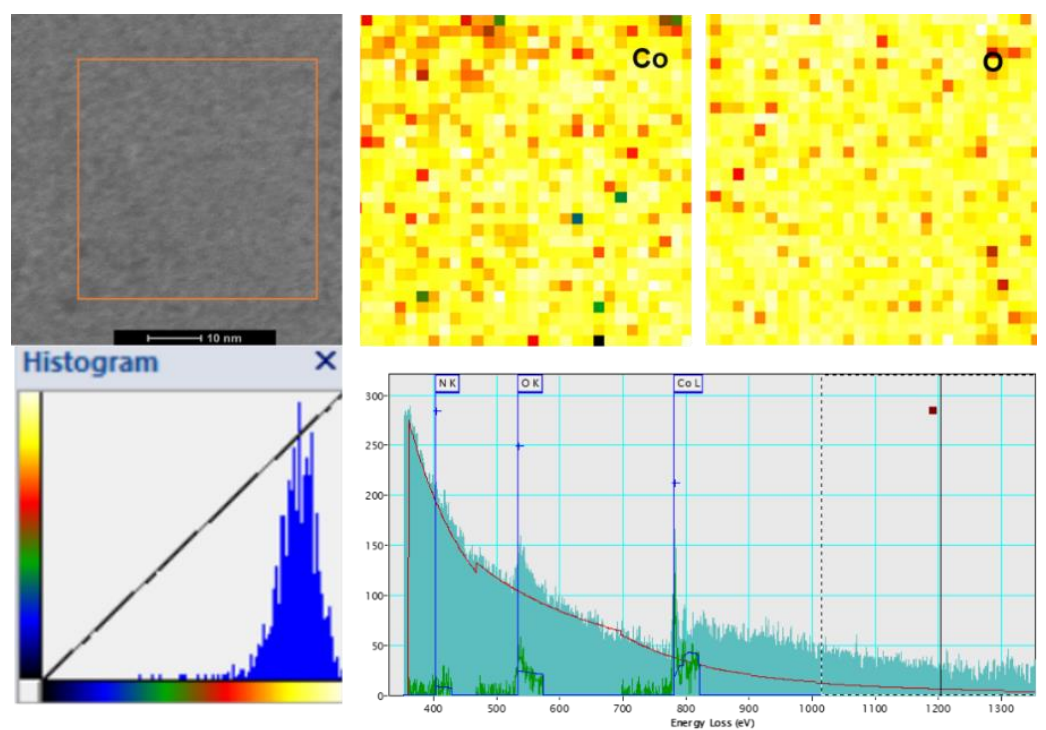

Figure S3. EELS mapping of $\mathrm{Co}(\mathrm{OH})_{2}$ nanosheets after plasma treatments. The ratio of $\mathrm{Co} / \mathrm{O}$ is close to $1: 1$. 


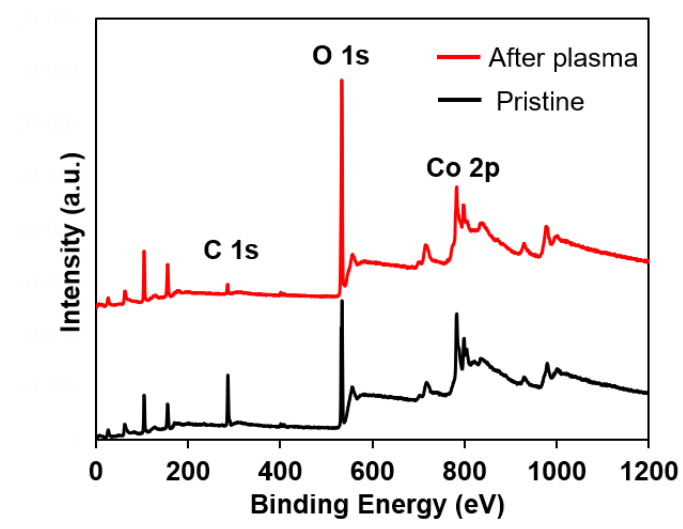

Figure S4. XPS of triangle nanosheets before and after $\mathrm{O}_{2}$ plasma treatments.

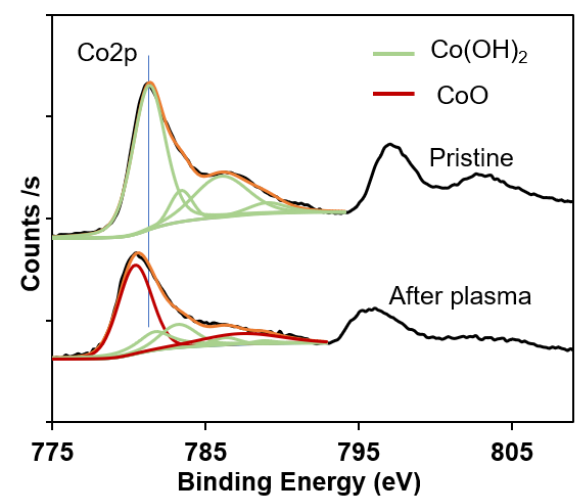

Figure S5. XPS of triangle nanosheets before and after $\mathrm{O}_{2}$ plasma treatments. The peak of Co $2 \mathrm{p}_{3 / 2}$ shifts from $781.6 \mathrm{eV}$ to $780.6 \mathrm{eV}$, and the peak of Co $2 \mathrm{p}_{1 / 2}$ shifts from $797.1 \mathrm{eV}$ to $796.2 \mathrm{eV}$ after the plasma treatments, which indicated that the $\mathrm{Co}(\mathrm{OH})_{2}$ is transferred into $\mathrm{CoO}$. 


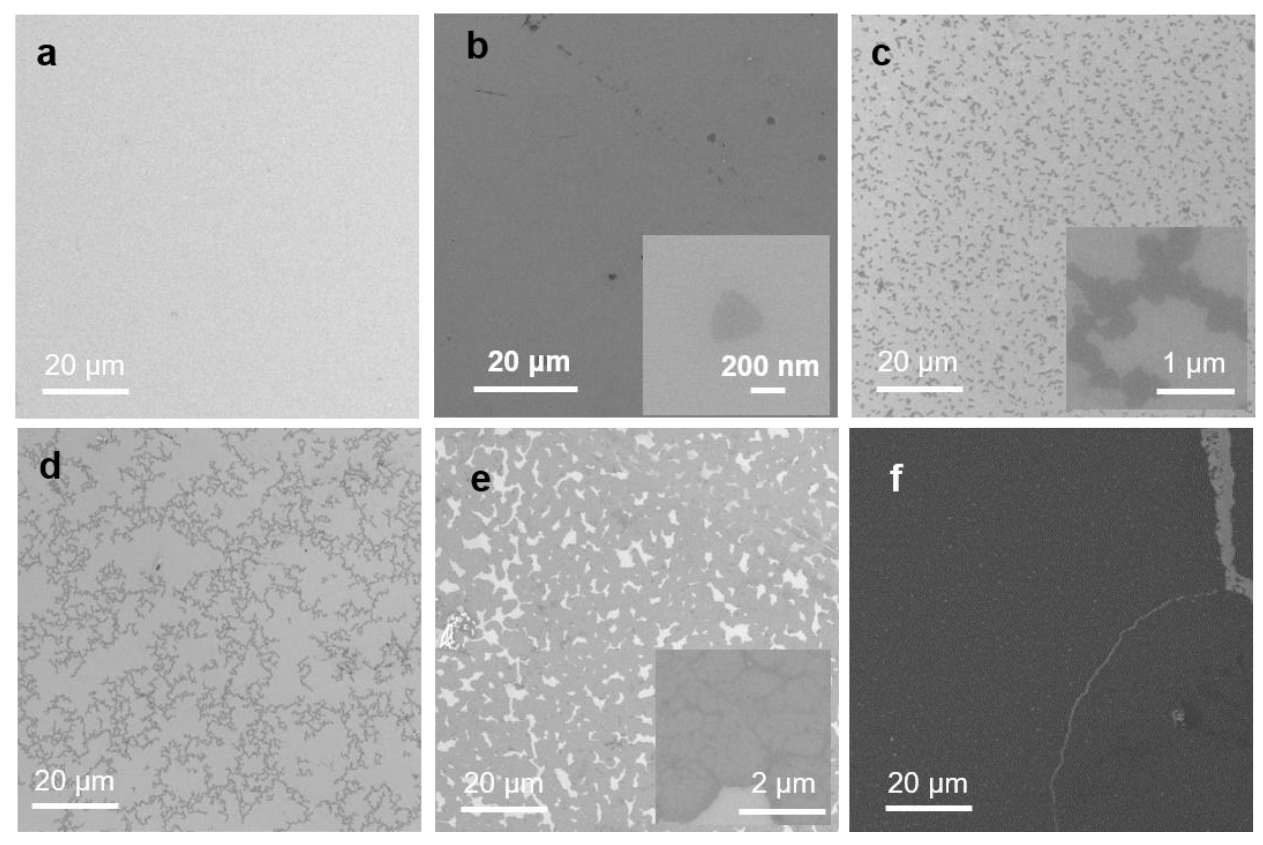

Figure S6. SEM images of $\mathrm{Co}(\mathrm{OH})_{2}$ nanostructures transferred from reactions with SOS/OAM = 9:1 at reaction time of a. $20 \mathrm{~min} ;$ b. $25 \mathrm{~min}$; and with mono SOS at reaction times of c. $20 \mathrm{~min}$; d. $25 \mathrm{~min}$; e. $40 \mathrm{~min}$; f. $100 \mathrm{~min}$.
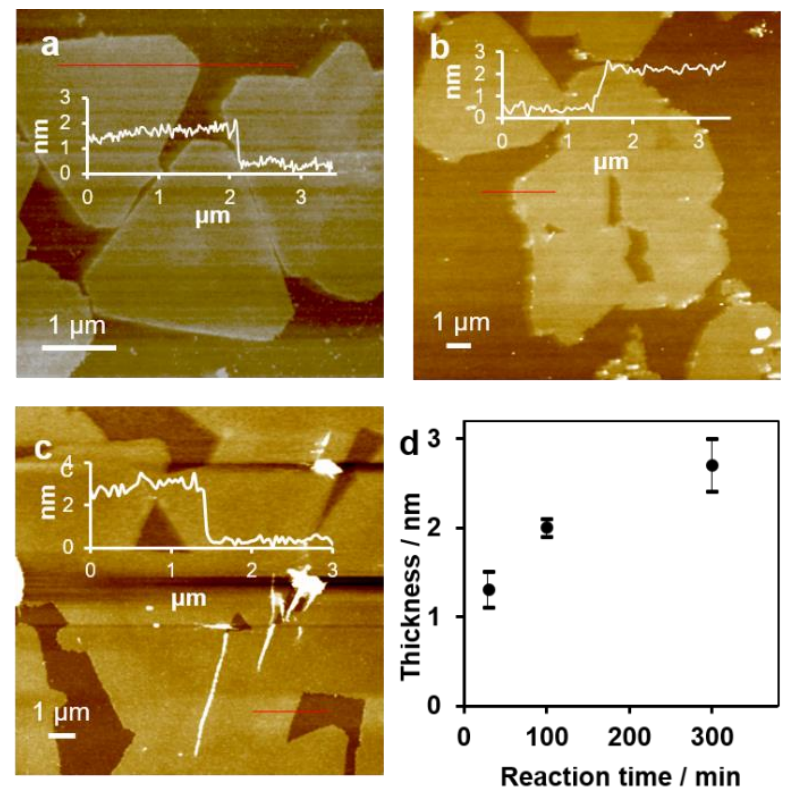

Figure S7. AFM of the as-prepared $\mathrm{Co}(\mathrm{OH})_{2}$ nanosheets with mixed surfactant $\mathrm{SOS} / \mathrm{OAM}=$ 9:1 at different reaction time of a. $30 \mathrm{~min}$; b. $100 \mathrm{~min}$; c. $300 \mathrm{~min}$; and d. the thickness changes of the nanosheets vs the reaction time. On each sample, we randomly chose a few areas to scan and measured the thickness of every single nanosheets within the scans. 


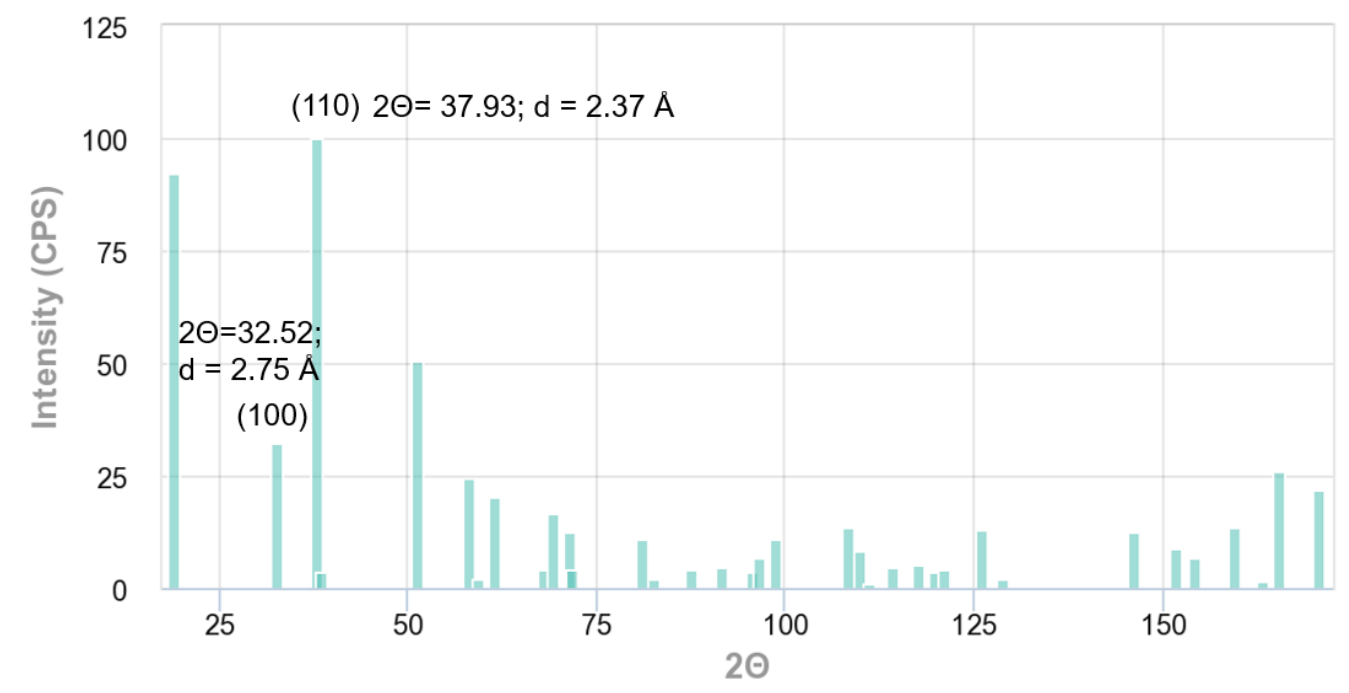

Figure S8. Calculated X-ray diffraction pattern for $\beta-\mathrm{Co}(\mathrm{OH})_{2 .}{ }^{8}$
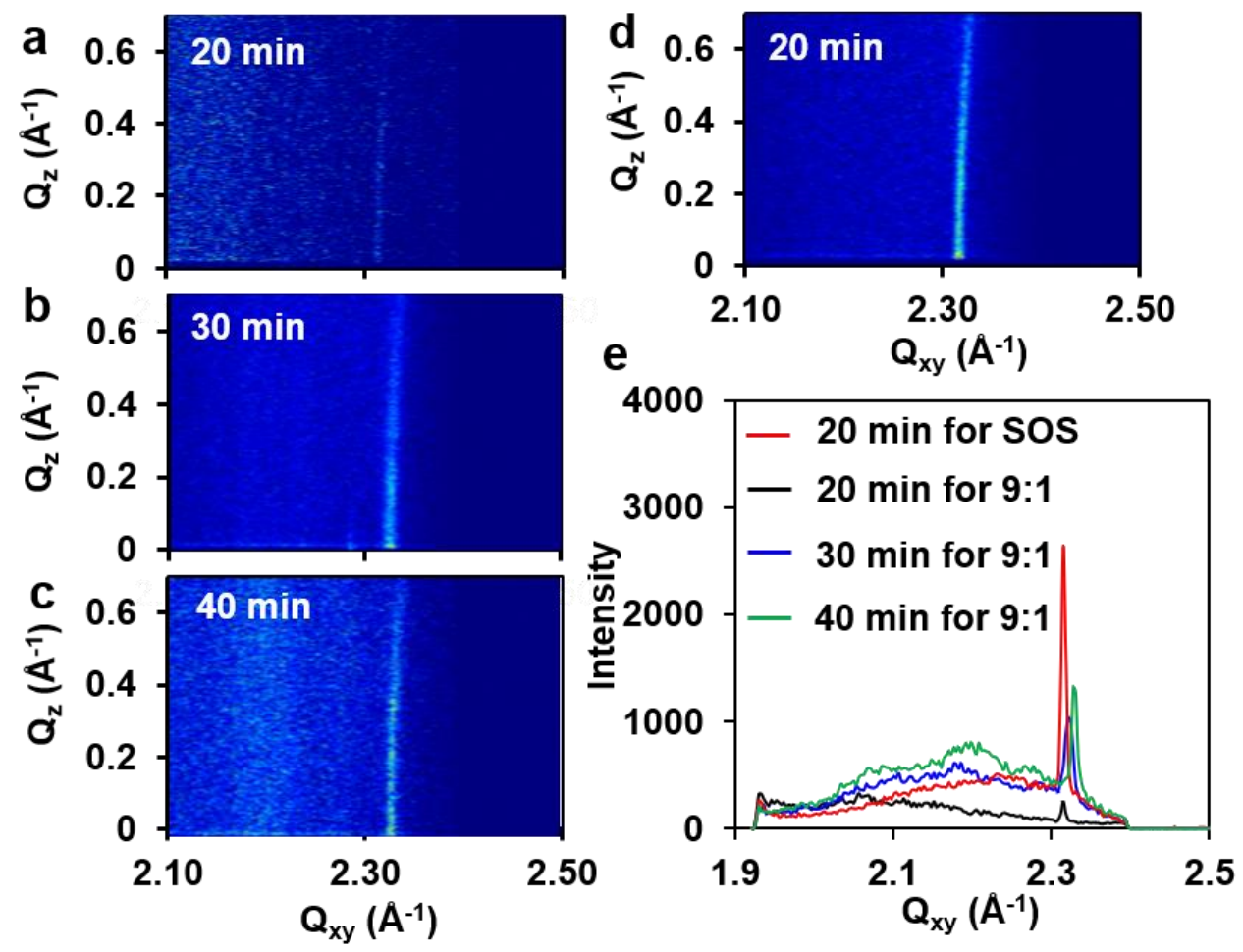

Figure S9. GID of $\operatorname{Co}(\mathbf{O H})_{2}$ nanosheets grown with $\mathrm{SOS} / \mathrm{OAM}=9: 1$ at reaction times of a. 20 $\mathrm{min} ; \mathbf{b} .30 \mathrm{~min}$; c. $40 \mathrm{~min}$; and d. with mono SOS at reaction time of $20 \mathrm{~min}$; e. Qz cut of GID data for nanosheets grown with mono SOS at $20 \mathrm{~min}$ (red line), and with SOS/OAM = 9:1 at $20 \mathrm{~min}$ (black line), $30 \mathrm{~min}$ (blue line) and $40 \mathrm{~min}$ (green line). 
Figure S10. MD simulation generated monolayer morphology at the interface for SOS/OAM $=7: 3$.
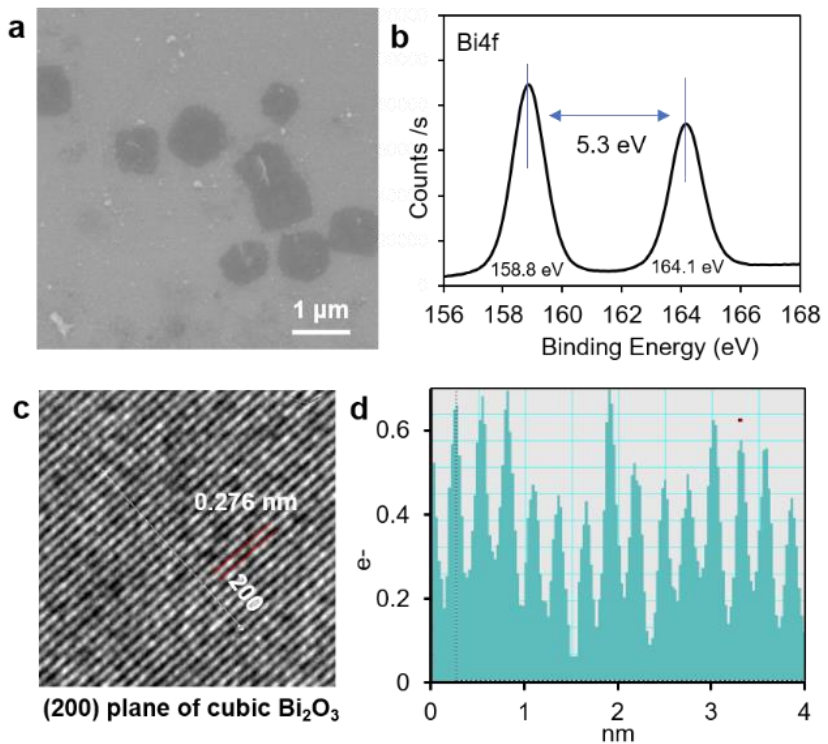

Figure S11. Characterization of cubic $\mathrm{Bi}_{2} \mathrm{O}_{3}$ nanosheets synthesized by mixed monolayer. a. $\mathrm{SEM}$ and $\mathbf{b}$. XPS of the cubic $\mathrm{Bi}_{2} \mathrm{O}_{3}$ nanosheets; $\mathbf{c}$. HR-TEM of the nanosheets; $\mathbf{d}$. Spacing between lattice along the white line in $\mathbf{c}$; According to the $\mathrm{Bi} 4 \mathrm{f} \mathrm{X-ray} \mathrm{photoelectron} \mathrm{spectroscopy} \mathrm{(XPS)}$ spectra of the nanosheets, the peaks centered at $164.1 \mathrm{eV}$ and $158.8 \mathrm{eV}$ can be assigned to $\mathrm{Bi} 4 \mathrm{f}_{5 / 2}$ and $\mathrm{Bi} 4 \mathrm{f}_{7 / 2}$ region, respectively. These binding energy values and peak separation $(\Delta=5.3 \mathrm{eV})$ were same as those obtained from $\mathrm{Bi}_{2} \mathrm{O}_{3}$.
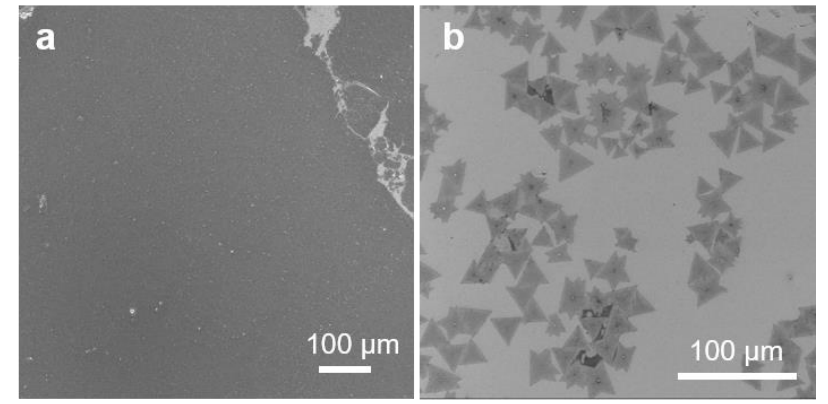
Figure S12. SEM images of Ni doped ZnO nanosheets obtained with surfactants of a. SOS; b. $\mathrm{SOS} / \mathrm{OAM}=7: 3$.
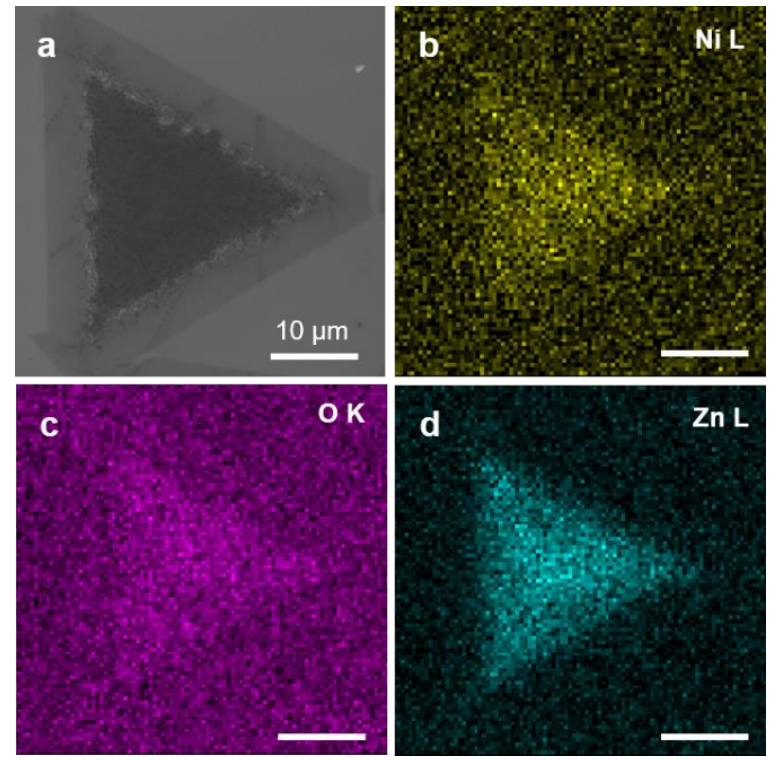

Figure S13. EDS of the Ni doped ZnO nanosheets obtained at SOS/OAM = 7:3.

a
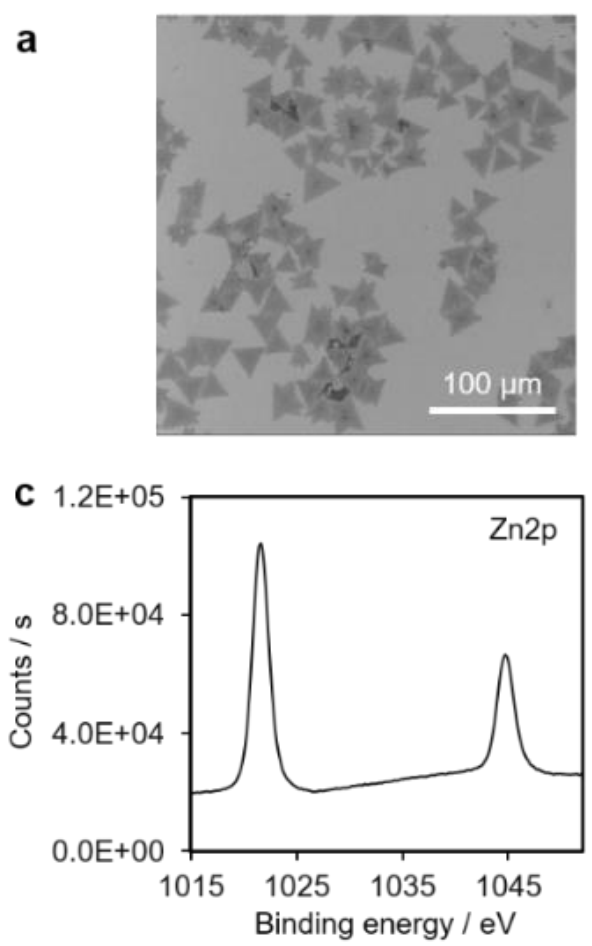
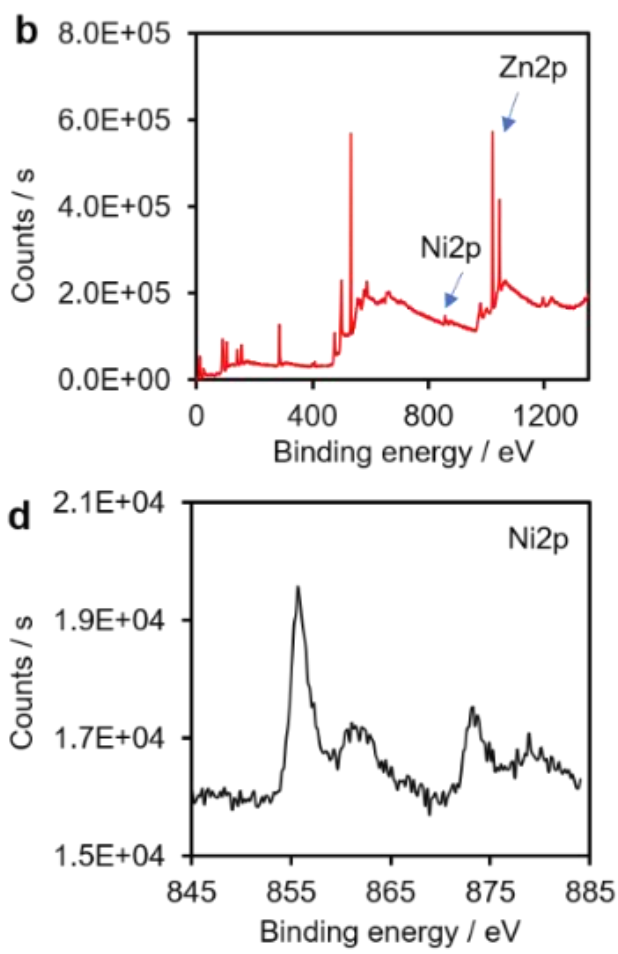
Figure S14. a. SEM of the triangle Ni doped $\mathrm{ZnO}$ nanosheets; $\mathbf{b}-\mathbf{d}$. XPS of the triangle Ni doped $\mathrm{ZnO}$ nanosheets. The nanosheet was synthesized with $10 \mathrm{mM} \mathrm{Zn}\left(\mathrm{NO}_{3}\right)_{2}$ and $15 \mathrm{mM} \mathrm{Ni}\left(\mathrm{NO}_{3}\right)_{2}$ at $60{ }^{\circ} \mathrm{C}$ for 100 min under mixed monolayer of SOS/OAM $=7: 3$.
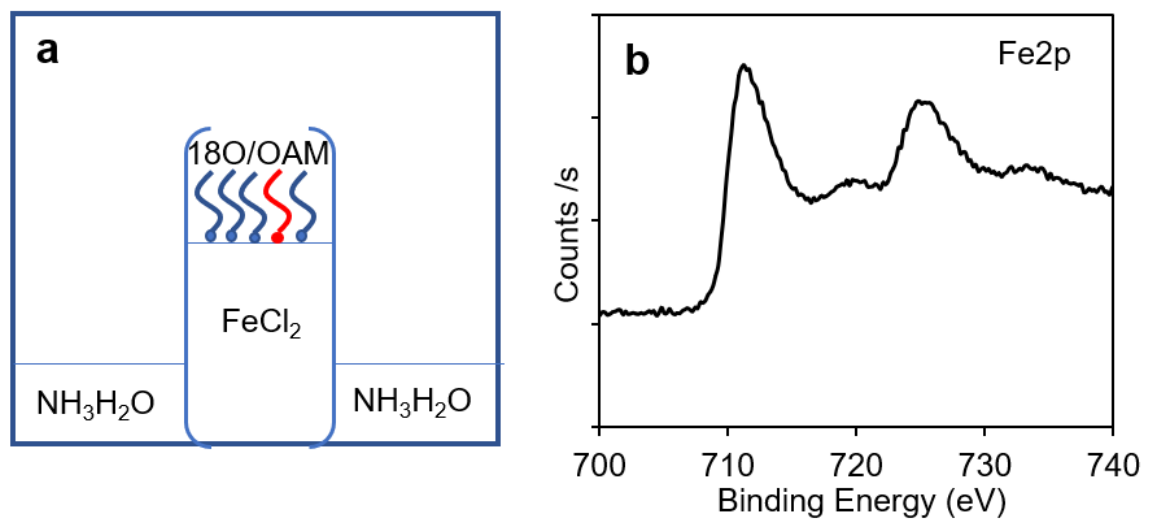

Figure S15. a. Scheme showing the $\mathrm{NH}_{3}$ diffusion method to synthesize iron oxide. b. XPS of iron oxide nanosheets synthesized by mixed 1-octadecanol (18O) and oleylamine (OAM) $(18 \mathrm{O} / \mathrm{OAM}=19: 1)$.
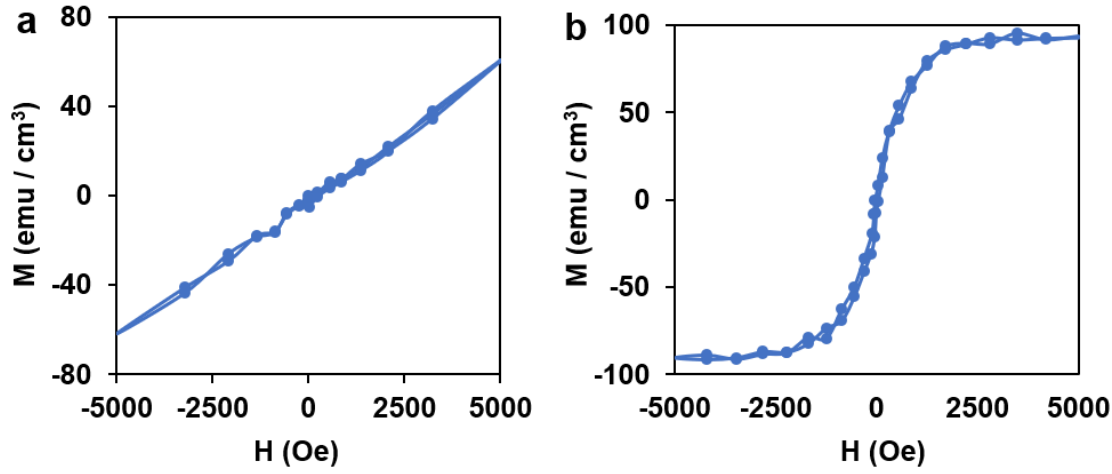

Figure S16. Ferromagnetic property of CoO nanosheets. a. $\mathrm{M}-\mathrm{H}$ loops of as-prepared $\mathrm{Co}(\mathrm{OH})_{2}$ nanosheets at $300 \mathrm{~K}$; b. M-H loops of $\mathrm{CoO}$ nanosheets after plasma treatments at $300 \mathrm{~K}$. The asprepared $\mathrm{Co}(\mathrm{OH})_{2}$ nanosheets were paramagnetic at room temperatures. After plasma treatments, the nanosheets transferred to $\mathrm{CoO}$, which showed strong ferromagnetism at $300 \mathrm{~K}$. Based on the $\mathrm{M}-\mathrm{H}$ measurement, a saturation magnetization of $91 \mathrm{emu} / \mathrm{cm}^{3}$ was observed for the $\mathrm{CoO}$ nanosheets. It has been reported that $\mathrm{CoO}$ thin film is paramagnetic or antiferromagnetic at room temperature. ${ }^{9-10}$ It has also been reported that Co vacancies could induce stable room temperature ferromagnetism in $\mathrm{CoO}$, and a $110 \mathrm{~nm}$ thick $\mathrm{CoO}$ thin film showed a saturation magnetization of $\sim 60 \mathrm{emu} / \mathrm{cm}^{3} .{ }^{10}$ Our $\mathrm{CoO}$ nanosheets with a thickness of $\sim 2 \mathrm{~nm}$ exhibited a larger saturation magnetization compared to those published results. This ferromagnetism might be associated with the high concentration of Co vacancy in nanosheets, which were induced and further stabilized by the monolayer surfactants attached on the surface of the nanosheets. These small thickness-related 
intriguing physical properties could open many opportunities for future research of 2D functional materials.
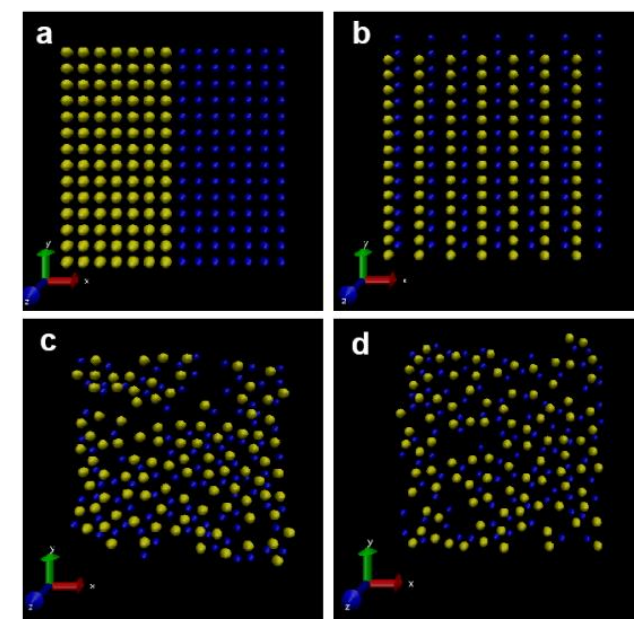

Figure S17. Initial and final configurations of the mixed SOS/OAM monolayer for 50:50 ratio. Yellow atoms represent $S$ in the SOS surfactant and blue atoms are $N$ in OAM. a and $\mathbf{b}$. Two different starting configuration for the mixed surfactant; $\mathbf{c}$ and $\mathbf{d}$. the corresponding configurations after $5 \mathrm{~ns}$ of simulations. These final configurations are qualitatively similar in that yellow atoms tend to be surrounded 3-4 blue atoms and vice versa.

\section{References:}

1. Schmid, N.; Eichenberger, A. P.; Choutko, A.; Riniker, S.; Winger, M.; Mark, A. E.; van Gunsteren, W. F., Definition and testing of the GROMOS force-field versions 54A7 and 54B7. European Biophysics Journal 2011, 40 (7), 843-856.

2. Oostenbrink, C.; Villa, A.; Mark, A. E.; Van Gunsteren, W. F., A biomolecular force field based on the free enthalpy of hydration and solvation: The GROMOS force-field parameter sets 53A5 and 53A6. Journal of Computational Chemistry 2004, 25 (13), 1656-1676.

3. Yin, X.; Shi, Y.; Wei, Y.; Joo, Y.; Gopalan, P.; Szlufarska, I.; Wang, X., Unit cell level thickness control of single-crystalline zinc oxide nanosheets enabled by electrical double-layer confinement. Langmuir 2017, 33 (31), 7708-7714.

4. Sammalkorpi, M.; Karttunen, M.; Haataja, M., Structural properties of ionic detergent aggregates: a large-scale molecular dynamics study of sodium dodecyl sulfate. The Journal of Physical Chemistry B 2007, 111 (40), 11722-11733.

5. Li, P.; Roberts, B. P.; Chakravorty, D. K.; Merz, K. M., Rational design of particle mesh ewald compatible lennard-jones parameters for +2 metal cations in explicit solvent. Journal of Chemical Theory and Computation 2013, 9 (6), 2733-2748.

6. Wang, L.; Hu, Y.; Liu, J.; Sun, Y.; Sun, W., Flotation and adsorption of muscovite using mixed cationic-nonionic surfactants as collector. Powder Technology 2015, 276, 26-33.

7. Berendsen, H. J. C.; Grigera, J. R.; Straatsma, T. P., The missing term in effective pair potentials. The Journal of Physical Chemistry 1987, 91 (24), 6269-6271.

8. Persson, K., Materials data on $\mathrm{Co}(\mathrm{HO})_{2}$ (SG:164) by Materials Project. 2014, DOI: $10.17188 / 1200651$. 
9. Alaria, J.; Cheval, N.; Rode, K.; Venkatesan, M.; Coey, J. M. D., Structural and magnetic properties of wurtzite $\mathrm{CoO}$ thin films. Journal of Physics D: Applied Physics 2008, 41 (13), 135004.

10. Negi, D. S.; Loukya, B.; Dileep, K.; Sahu, R.; Nagaraja, K. K.; Kumar, N.; Datta, R., Robust room temperature ferromagnetism in epitaxial $\mathrm{CoO}$ thin film. Applied Physics Letters 2013, 103 (24), 242407. 